\title{
The Survey of the Effectiveness of Feedback from Minicourse Video on English Writing in Senior School
}

Tao Yang

School of Foreign Language, China West Normal University, Nanchong, Sichuan ,China

\begin{abstract}
This paper centers on investigating the efficacy of minicourse given to 131 senior one students over one assignment in an intermediate EFL writing context. Through an array survey of 122 items, it scrutinizes students perceptions, attitudes and use of minicourse feedback. Results indicate that compared traditional written feedback or other forms, students show positive feedback to the introduction of minicourse feedback.
\end{abstract}

Keywords: EFL writing; minicourse feedback; feedback on writing

\section{Introduction}

1.1 Research background

1.1.1 The English writing in the new English curriculum for Chinese senior schools

For EFL teaching and learning, teachers should pay attention to students' life experiences and cognitive level so that they can select topics closely related to students' life, and create rich and diverse discourses. The selective course stipulates that learners should acquire output skills, including recreating the imaginary experiences and other things, commenting on the points, affairs, and other experiences, vividly expressing one's own emotions and thinking, composing different discourses for different intentions, making essay more coherent by using conjunctions, expressing creatively in some special vocabularies, grammar, graph, voice, chart and other non-verbal resources.

It can be found that both obligatory course and selective course emphasize the coherence in discourse although the ability levels are different from each other. In other words, EFL writing teaching and learning should focus on not only the accuracy of language, but also the coherence of the language.

1.1.2 The significance of writing feedback

Recently, L2 writing, the core skill accepted in foreign language teaching, can also lead to improvements in reading comprehension (Hebert, Gillespie \& Graham, 2013), reading ability (Graham \& Herbert, 2011), and overall academic achievement (Bangert-Drowns, Hurley \& Wilkinson, 2004). Considering the importance of writing skill, feedback is playing a vital role in L2 writing, which has become a hot topic to EFL teachers. Feedback in EFL writing is regarded as a form of mediation from a social-cultural construct (Lee I., 2017). Briefly, the mediated learning experience is the key of feedback. Providing feedback for students' compositions is an important part in EFL writing teaching. Luckily, EFL writing feedback has shifted its focus on the superficial outcome of writing tasks to the dynamic and complicated writing 
evaluation. Keh (1990:302) pointed out that feedback is a dispensable section during the writing process.

\subsubsection{The limitation of current state of EFL writing feedback}

The conventional feedback practices in Chinese context actually are not effective enough. For example, in terms of teachers' feedback, the product-oriented method is welcomed in the traditional Chinese EFL teaching, and its feedback is an add-on at the end of the learning serving to help learners master accurate language knowledge after writing practice. Therefore, teachers usually apply summarized and one-dimensional feedback (Lo \& Hyland, 2007). That is to say, the corrective feedback contains a score and brief comments from teachers in most cases. This stereotype follows a mode: learners' draft $\rightarrow$ teachers' revising and scoring $\rightarrow$ collective feedback in class. Till now, it is widely used in most Chinese schools. However, teachers play little attention to systematic feedback and revising, such as lacking feedback method, lacking effective feedback, and lacking communication between teachers and students after receiving feedback (Xu K., 2011).

The feedback with technology incorporated into its approaches is increasingly popular. However, the automatic scoring feedback cannot completely replace the traditional feedback in the classroom, but it can act as the complementary for class teaching (Wang S.W., 2011). The feedback from automatic system is limited, so it fails to response to students' mistakes accurately and give specific revising suggestions. Besides, its mechanical feedback cannot help learners improve their sensibility to mistakes. (Lv T.T., Zhang H. \& Wang N., 2015)

The reasons for these problems existing in feedback are various. From the description above, the conclusions that can be drawn: firstly, most teachers pay much attention to the form of feedback but ignore the real interaction among all agencies during the learning process and fail to scrutinize the information conversion method and conversion ratio; secondly, learners remain passive whether in teacher's feedback or in the feedback of self or peers.

1.1.4 The current state of minicourse EFL writing feedback

In recent two years, the bulk of newest studies draw attention to the application first in college English teaching, (Zhao D.D., 2016; Liang W., 2016; Liu N., 2015) followed by middle school English (Yang F.G, 2018; Gan P., Hong W.Y., 2017; Chao Y.Q., 2016). The application of minicourse EFL writing in high school can provide writing topic, cultural background, writing techniques for students and its vivid demonstration, writing practices, writing feedback and other provisions help to grasp students' attention and interest (Ma G.Q., 2015). A few researches on EFL writing also make headway. Feng Yanxia (2019) pointed out that efficient English writing teaching means effective knowledge input and good language output and writing ability, which is exactly the teaching objective for EFL writing. The minicourse, to some extent, helps to achieve effective language input by providing contextualized learning environment and abundant perception to facilitate knowledge intake for learners.

Altogether, while an increasing number of researches on the application of minicourse in EFL teaching have been made, there is still a big gap that needs to explore in terms of EFL writing.

\section{Literature Review}

\subsection{The key concepts}

In order to specify "writing feedback", it is necessary to figure out what is "feedback" firstly. The term "feedback" was first coined by Nobel laureate Karl Ferdinand Braun to explain coupling between components of an electronic circuit in engineering system. And then the "feedback" means "a mechanism which provides the learner with information regarding the success or failure of a given process." (Leeman, 2007: 112) The American Heriage Dictionary (2006) regards the feedback as returning a portion of the input in a process or a system to the output.

The feedback in writing teaching from Keh (1990) is "the input provided by the reader to the author, the purpose is to 
provide information for the author to modify his own articles." Arndt (1991) treated feedback as an input that the reader offers to the author about L2 writing. Butler (1995) defined feedback as the information teachers give learners about their learning process and achievement. Rod Ellis (1985) provided conception of feedback as the response that learners received about their learning effort. Wlodkowski (2008) defined feedback as the information learners receive about their work.

To summarize, the conceptions of feedback in the fields of EFL teaching are quite different from that in technology. Some researchers defined the feedback from the teachers' point (Keh, 1990; Arndt, 1993; Butler, 1995), while others defined it from the learners' point (Ellis, 1985; Wlodkowski, 2008).

2.2 Previous studies and findings

2.2.1 Previous studies aboard

At aboard, rare experimental studies directly focus on the minicourse feedback on EFL/ESL writing feedback. But there are still some similar researches aiming at video-course, screencast and audio visual feedback among international academia. For instance, there was a study comparing audio feedback and written feedback on writing assignments (Eric C. Nemec, Mattew Dintzer, 2016). The study results showed that learners in most cases preferred audio feedback, which seemed to be affective alternative for feedback on EFL writing assignments and felt it more individualized in nature. Kelly J. Cunningham (2019) conducted an exploratory study to investigate the efficacy of screencast feedback, and also compared the text feedback and screencast feedback. The study found that video feedback offered a $33 \%$ time savings. Another research by Kelly J. Cunningham (2019) investigated how the mode of video and text feedback changes learners' interpersonal aspects. And it found that video feedback performs better in promoting learners' autonomy. The much more volition of these learners helps to treat instructor's suggestion as more possible options within these feedbacks. There was still study operating in Iranian EFL intermediate students to evaluate the effect of text and audio corrective feedback (CF). The result indicated that both text and audio CF are benefit to EFL writing development. The difference is that audio CF is more effective than text CF (Ehsan Rassaei, 2019). Research about linguistically-tailored video feedback was made to test effects of linguistically-tailored video feedback on an inter-based expressive writing intervention and found that linguistically-tailored video feedback may change modality if it is computer-based intervention (Wang Y.J., Shang H.F. \& Briody P. 2012).

\subsubsection{Previous studies at home}

The minicourse is also called micro-lecture or microcourse in Chinese mainland. In Chinese context, the minicourse, as a emerging and prospective thing, is mainly put in application research for subjects and teacher training whether for teaching competition or learning outside the classroom now. Zhang Xia (2014) developed two kinds of micro-lectures, namely "introducing micro-lecture within entity classroom" and "using micro-lecture before class". The research result found that students kept positive attitudes, and the two micro-lecture modes can accelerate learning effect. Li Qing (2018) made an experimental research on undergraduates, during the process, six writing assignments were scored both by Pigai system and teacher, and then the teacher pointed out which minicourse should be learned for each individuals. The research result indicated that it has positive impact on learners' writing proficiency.

In conclusion, there are many advantages in the features of micro-lecture, which make it possible to put the microlecture in use. However, its application in EFL writing feedback is rarely used during real classroom teaching.

\section{Methodology}

3.1 Research questions

(1) Students' engagement, perception and preferences impact of minicourse feedback.

(2) Whether the Minicourse feedback helps to improve learners' engagement? 


\subsection{Participants}

The study includes pool of participants of 131 senior one students who participated in two English composition classes with 80 minutes. The 131 students are from 3 moderate level classroom from a high school in Nanchong. And the writing instructor involved in this study is their teachers. Each of them is a volunteer without any inducement.

\subsection{Instruments}

The survey adopted from E.J. Vincelette and T. Bostic's Assessing Writing (2013, 18: 257-277) to assess the efficacy of Minicourse feedback. Items of each survey are adjusted to match this study. The survey is composed with nineteen items and four dimensions, namely attending/engagement, incorporation of revision, feedback quality/quantity and preference. All these items are four-point Likert scale. Strongly agree with a score of 4; agree with a score of 3; disagree with a score of 2; Strongly disagree with a score of 1 . To make sure a good quality of questionnaires. These surveys are handed out by the instructors, and directions are clearly told to participants in advance.

Table1. Students' perceptions of Minicourse feedback

\begin{tabular}{|c|c|c|c|c|c|}
\hline \multicolumn{6}{|c|}{ Frequency $(\mathrm{n}=122)$} \\
\hline & Strongly agree & Agree & Disagree & Strongly disagree & Mean \\
\hline \multicolumn{6}{|c|}{ Theme 1-Attending/Engagement: } \\
\hline 1. & $68(56 \%)$ & $54(44 \%)$ & 0 & 0 & 3.6 \\
\hline 2. & $52(43 \%)$ & $68(56 \%)$ & $2(1 \%)$ & 0 & 2.9 \\
\hline 3. & $50(41 \%)$ & $71(58 \%)$ & $1(1 \%)$ & 0 & 3.4 \\
\hline \multicolumn{6}{|c|}{ Theme2-Incorporation of Revision: } \\
\hline 4. & $73(60 \%)$ & $48(39 \%)$ & $1(1 \%)$ & 0 & 3.6 \\
\hline 5. & $76(62 \%)$ & $46(38 \%)$ & 0 & 0 & 3.6 \\
\hline 6. & $71(58 \%)$ & $51(42 \%)$ & 0 & 0 & 3.6 \\
\hline 7. & $78(64 \%)$ & $44(36 \%)$ & 0 & 0 & 3.6 \\
\hline \multicolumn{6}{|c|}{ Theme4_Feedback quality/quantity: } \\
\hline 8. & $54(44 \%)$ & $65(53 \%)$ & $3(3 \%)$ & 0 & 3.4 \\
\hline 9. & $57(47 \%)$ & $64(52 \%)$ & $1(1 \%)$ & 0 & 3.4 \\
\hline 10. & $51(42 \%)$ & $69(56 \%)$ & $2(2 \%)$ & 0 & 3.4 \\
\hline 11. & $66(54 \%)$ & $56(46 \%)$ & 0 & 0 & 3.5 \\
\hline 12. & $54(44 \%)$ & $66(54 \%)$ & $2(2 \%)$ & 0 & 3.4 \\
\hline 13. & $50(41 \%)$ & $71(58 \%)$ & $1(1 \%)$ & 0 & 3.4 \\
\hline 14. & $54(44 \%)$ & $66(54 \%)$ & $2(2 \%)$ & 0 & 3.4 \\
\hline 15. & $65(53 \%)$ & $55(45 \%)$ & $2(2 \%)$ & 0 & 3.5 \\
\hline 16. & $53(43 \%)$ & $67(55 \%)$ & $2(2 \%)$ & 0 & 3.4 \\
\hline 17. & $44(36 \%)$ & $68(56 \%)$ & $10(8 \%)$ & 0 & 3.3 \\
\hline 18. & $45(37 \%)$ & $76(62 \%)$ & $1(1 \%)$ & 0 & 3.4 \\
\hline 19. & $69(57 \%)$ & $53(43 \%)$ & 0 & 0 & 3.6 \\
\hline
\end{tabular}

Four-point Likert scale

(4=Strongly agree; $1=$ Strongly disagree) 


\section{Results and Discussion}

131 pieces of students' questionnaires were handed out, 126 questionnaires were recalled and 122 of them are valid questionnaires. The result of questions related to students' perceptions of minicourse feedback is presented in table1. All these questions are divided into three scales. The mean score about the theme1-attending or engagement is between 2.9-3.6. The mean score about the incorporation of revision is 3.6. The mean score about the feedback quality/quantity is between 3.3-3.5. This result shows that at least $98 \%$ of students are engaged in EFl writing feedback; $99 \%$ of students are well integrated into the revision through minicourse feedback; $90 \%$ or above students provide a positive perception towards feedback quality.

\section{Conflicts of Interest}

The author declares no conflicts of interest regarding the publication of this paper.

\section{References}

[1] Arndt V. (1991). Process writing. Harlow: Longman. Zamel, V. (1985). Responding to student writing. TESOL Quarterly, 21, 697-715

[2] Ehsan R. (2019). Computer-Mediated Text-Based and Audio-Based Corrective Feedback. Perceptual Style and L2 Development, (82): 97-110.

[3] Ellis R. (2009). Corrective feedback and teacher development. L2 Journal, 1(1), 3-18.

[4] Eric C.N. and Matthew D. (2016). Comparison of Audio Versus Written Feedback on Writing Assignments. Currents in Pharmacy Teaching and Learning, (8): 155-159

[5] Graham S. and Herbert, M. (2011). Writing to read: A Meta-Analysis of the Impact of Writing and Writing Instruction on Reading. Harvard Educational Review, 81(4): 710-744.

[6] Hebert M., Gillespie A. and Graham S. (2013). Comparing Effects of Different Writing Activities on Reading Comprehension: A Meta-Analysis. Reading and Writing, 26(1): 111-138.

[7] Julia L. and Fiona H. (2007). Enhancing Students' Engagement and Motivation in Writing: The Case of Primary Students in Hong Kong. Journal of Second Language Writing, (16): 219-237.

[8] Keh C. L. (1990). Feedback in the Writing process: A Model and Methods for Implementation. ELT Journal, 44 (4): 294- 304.

[9] Lee I. (2017). Technology in Classroom L2 Writing Assessment and Feedback. Classroom Writing Assessment and Feedback in L2 School Contexts. Springer, Singapore.

[10] Simmons L. K. (2010). Enhancing Adult Motivation to Learn: A Comprehensive Guide for Teaching All Adults By Raymond J. Wlodkowski. Teaching Theology \& Religion, 13(2): 188-190.

[11] Tribble C. (1996). Writing. Oxford University Press, Oxford.

[12] Woo M.M., Chu S.K.W. and Li X. (2013). Peer-feedback and Revision Process in a Wiki Mediated Collaborative Writing. Education Tech Research Dev, (61): 279-309 .

[13] Chao Y.Q. (2016). The Design and Application of High School English Micro-courses. E-Education Research, (S1): 143-145.

[14] Li Q. (2018). The Experimental Study of Micro-courses Assisting Differential Teaching of English Writing in Universities. Crazy English, (4): 31-34.

[15] Lv T.T., Zhang H. and Wang N. (2015). The Study of Impact from Automatic Feedback on College Students' English Writing Based on the Digital Writing Resource platform. E-Education Research, (06): 95-101. 
[16] Xu K. (2011). A Study on Teachers' Feedback to English-writing Teaching in Senior High School. Shandong Normal University, (08).

[17] Zhen M.X. (2018). A Study on College English Writing Feedback Model Based on Atomatic Feedback Plus Teacher Feedback. Wuhan University of Science and Technology, Hubei.

[18] Zhang X. (2014). The Research of Design, Development and Application on Micro-Curriculum. Guangxi Teachers Education University, (02). 